\title{
Solution for Injection in Pre-filled Pen
}

National Cancer Institute

\section{Source}

National Cancer Institute. Solution for Injection in Pre-filled Pen. NCI Thesaurus. Code C149918.

Medicinal product consisting of a solution for injection presented in a pre-filled pen. 